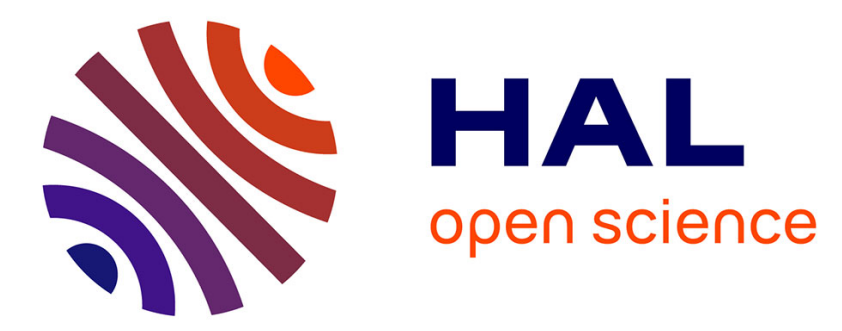

\title{
Effect of H-implantation in the local elastic properties of silicon crystals
}

\author{
Shay Reboh, F. Rieutord, L. Vignoud, F. Mazen, Nikolay Cherkashin, M. \\ Zussy, D. Landru, C. Deguet
}

\section{- To cite this version:}

Shay Reboh, F. Rieutord, L. Vignoud, F. Mazen, Nikolay Cherkashin, et al.. Effect of H-implantation in the local elastic properties of silicon crystals. Applied Physics Letters, 2013, 103 (18), pp.181911. 10.1063/1.4828659 . hal-01736023

\section{HAL Id: hal-01736023 https://hal.science/hal-01736023}

Submitted on 22 Mar 2018

HAL is a multi-disciplinary open access archive for the deposit and dissemination of scientific research documents, whether they are published or not. The documents may come from teaching and research institutions in France or abroad, or from public or private research centers.
L'archive ouverte pluridisciplinaire HAL, est destinée au dépôt et à la diffusion de documents scientifiques de niveau recherche, publiés ou non, émanant des établissements d'enseignement et de recherche français ou étrangers, des laboratoires publics ou privés. 


\section{Effect of $\mathrm{H}$-implantation in the local elastic properties of silicon crystals}

S. Reboh, F. Rieutord, L. Vignoud, F. Mazen, N. Cherkashin, M. Zussy, D. Landru, and C. Deguet

Citation: Appl. Phys. Lett. 103, 181911 (2013); doi: 10.1063/1.4828659

View online: https://doi.org/10.1063/1.4828659

View Table of Contents: http://aip.scitation.org/toc/apl/103/18

Published by the American Institute of Physics

\section{Articles you may be interested in}

Lattice strain of hydrogen-implanted silicon: Correlation between X-ray scattering analysis and ab-initio simulations

Journal of Applied Physics 113, 153511 (2013); 10.1063/1.4800538

Kinetic evolution of blistering in hydrogen-implanted silicon

Applied Physics Letters 103, 031908 (2013); 10.1063/1.4813858

Crystalline to amorphous transformation in GaAs during $\mathrm{Kr}$ ion bombardment: A study of elastic behavior Journal of Applied Physics 66, 152 (1989); 10.1063/1.343895

Fracture dynamics in implanted silicon

Applied Physics Letters 107, 092102 (2015); 10.1063/1.4930016

Surface self-diffusion of silicon during high temperature annealing

Journal of Applied Physics 115, 134903 (2014); 10.1063/1.4870476

Development of microcracks in hydrogen-implanted silicon substrates

Journal of Applied Physics 114, 123513 (2013); 10.1063/1.4821239

\section{Scilight}

Sharp, quick summaries illuminating the latest physics research

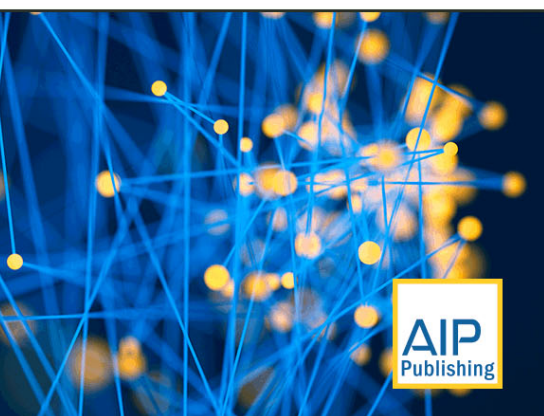




\title{
Effect of $\mathrm{H}$-implantation in the local elastic properties of silicon crystals
}

\author{
S. Reboh, ${ }^{1, a)}$ F. Rieutord, ${ }^{2}$ L. Vignoud,${ }^{1}$ F. Mazen, ${ }^{1}$ N. Cherkashin, ${ }^{3}$ M. Zussy, ${ }^{1}$ D. Landru, ${ }^{4}$ \\ and C. Deguet ${ }^{1}$ \\ ${ }^{1}$ CEA, LETI, Minatec Campus, 17 rue des Martyrs, 38054 Grenoble Cedex 9, France \\ ${ }^{2}$ CEA, INAC, 17 rue des Martyrs, 38054 Grenoble Cedex 9, France \\ ${ }^{3}$ CEMES, CNRS UPR 8011 and Université de Toulouse, 29 rue Jeanne Marvig, 31055 Toulouse, France \\ ${ }^{4}$ Soitec, Parc Technologique des Fontaines, 38190 Bernin, France
}

(Received 30 July 2013; accepted 15 October 2013; published online 1 November 2013)

\begin{abstract}
In contrast to previous reports, where the modification of elastic constants of semiconductors irradiated with heavy ions was related to crystalline to amorphous transition, here we show that hydrogen implantation causes a dramatic modification of the shear modulus of $\mathrm{Si}$ at relatively low levels of crystalline damage. To study the system, we developed an alternative and rather general method to determine the shear modulus of the buried implanted layer. We use elasticity theory to link two simple measurements: (i) the wafer curvature to extract the in-plane stresses and (ii) x-ray diffraction to determine strains in the implanted layer. (C) 2013 AIP Publishing LLC. [http://dx.doi.org/10.1063/1.4828659]
\end{abstract}

Silicon-On-Insulator (SOI) is a fundamental substrate for building high-performance and low-power portable electronics, including innovative 3D architectures of Metal-Oxide-Semiconductor-Field-Effect-Transistors. ${ }^{1-3}$

SmartCut ${ }^{\mathrm{TM}}$, the technology allowing the fabrication of such engineered substrates by layer separation and wafer bonding, is based on hydrogen and/or light gas ion implantation. ${ }^{4,5}$ Essentially, the bombardment with $\mathrm{H}^{+}$produces a buried damage layer in the Si substrate at a typical depth of a few tens to hundreds of nanometers, depending on the acceleration voltage of the ions. The H-rich layer created contains disruptive crystalline defects ranging from broken $\mathrm{Si}-\mathrm{Si}$ bonds passivated by $\mathrm{H}$, to vacancy-hydrogen complexes and small clusters of point defects such as spherical and plate-like cavities filled with gas. ${ }^{4-11}$ Upon annealing, larger defects in the form of nanocracks are observed. Nanocracks evolve into larger microcracks, ${ }^{12,13}$ resulting in a complete and catastrophic fracture of the wafer along the implanted layer. ${ }^{10}$ Different studies have described the thermal evolution of the microstructure, where the elastic energy and, in general, the mechanics of the system play an elemental role. ${ }^{10,14-16}$ An aspect, which has been less explored, is the extent to which the irradiation damage modifies the elastic properties of this system. In intermetallic compounds, for example, modification of the elastic properties was observed after irradiation with heavy ions at high energy regimes (typically $>1 \mathrm{MeV}) .{ }^{17-20}$ In semiconductors such as $\mathrm{Si}, \mathrm{Ge}$, and GaAs, a change of the elastic constants by irradiation with heavy ions has been linked to extremely high levels of damage, where a crystalline to amorphous transition of the material occurs. ${ }^{21-25}$

Here, we investigate the modification of elastic properties in light ions/low energy implanted Si crystals. For this, we developed a method that relies on elasticity theory to combine the in-plane biaxial stress obtained by measuring the wafer curvature, with the corresponding orthogonal lattice strain measured by x-ray diffraction (XRD). The

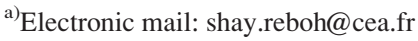

experiments were performed in (110) Si crystals implanted with $\mathrm{H}$ at different fluences. In contrast with the previous literature, we show that for relatively low levels of damage, the implantation of $\mathrm{H}$ causes the shear modulus of the implanted/damaged crystal to decrease significantly, and we quantify the change. Additionally, Secondary Ion Mass Spectroscopy (SIMS) was used to establish the correlation between the lattice strain and the local concentration of $\mathrm{H}$. For high fluence regimes, strain increases faster than the $\mathrm{H}$-concentration. From elasticity theory, the behavior can be explained either by an evolution of the volume dilatation per implanted ion or by an evolution of the Poisson ratio of the material with accumulated crystal damage.

Czochralski grown $300 \mathrm{~mm}$ (110)-Si wafers of $725 \mu \mathrm{m}$ thickness were implanted with $\mathrm{H}^{+}$ions at $32 \mathrm{keV}$ to the fluence $\Phi$ of $0.25,0.5,1,2,4$, and $6 \times 10^{16} \mathrm{H}^{+} / \mathrm{cm}^{2}$. The substrates were kept at $20^{\circ} \mathrm{C}$ during implantation. The depth-concentration profiles of $\mathrm{H}$ were measured by SIMS using a $\mathrm{Cs}^{+}$beam and an energy of $12 \mathrm{keV}$. The introduction of $\mathrm{H}$ and lattice disorder associated with the implantation process results in an average dilatation per implanted ion of the Si lattice $\left(\frac{\Delta V}{V}\right)^{H}$ where $\mathrm{V}$ is the volume of a Si lattice cell and $\Delta V$ is the average change of cell volume per implanted ion. Assuming that the average dilatation is isotropic over a large number and possible configuration of defects, ${ }^{26}$ the substrate stiffness imposes a restriction to relaxation along the directions parallel to the surface. This gives rise to a compressive in-plane stress. By Poisson reaction, a tensile out-of-plane strain $\varepsilon_{\perp}$ develops in the layer, written as ${ }^{27}$

$$
\varepsilon_{\perp}=-e_{\|}\left(\frac{1+\nu_{i}}{1-\nu_{i}}\right)
$$

where $\nu_{\mathrm{i}}$ is the Poisson ratio of the damaged layer and the in-plane elastic strain $e_{\|}=-\frac{1}{3}\left(\frac{\Delta V}{V}\right)^{H} N^{H}$, with $N^{H}$ the average number of $\mathrm{H}$ atoms per Si lattice unit. To determine $\varepsilon_{\perp}$, the substrates were investigated by XRD. ${ }^{28-30}$ Longitudinal 
$\theta / 2 \theta$ scans in the vicinity of the 220 Bragg reflection were performed at the BM32 beam line of the European Synchrotron Radiation Facility (ESRF), using a beam energy of $18 \mathrm{keV}$. The incident beam divergence was typically $0.05 \mathrm{mrad}$ with an energy resolution of $\Delta \mathrm{E} / \mathrm{E}=10^{-4}$. Simulations of the XRD curves, to reconstruct the depth-distribution of strain in the materials, were done using a web-based code provided by the Argonne National Laboratory. $^{31}$

The in-plane strain $\varepsilon_{\|}$developed in the implanted region is associated with an in-plane stress $\sigma_{\|}$. Provided that the implantation process modifies a superficial region which is thin compared to the thick substrate, we can use Stoney's equa$\operatorname{tion}^{32}$ to calculate the mean value of stress in the layer $\sigma_{\|}^{\text {mean }}$ by measuring the curvature of the implanted wafers. This curvature was determined by monitoring the wafer-bow according to the Semiconductor Equipment and Materials International Standards. ${ }^{33}$ For this, we used a FRT MicroProf ${ }^{\circledR}$ tool with a non-contact optical sensor to measure the distances $\mathrm{Z}$ of the central point of the wafer to a reference situated in the plane of support. The procedure is done on both sides of the wafers to remove the effects of gravity. The effective radius of curvature $\mathrm{R}$ of the wafer is defined as $\frac{1}{R}=\left(\frac{8 B_{A i}-8 B_{B i}}{D^{2}}\right)$, with $\mathrm{D}$ being the diameter of the wafer and $B=\frac{Z_{F S}-Z_{B S}}{2}$ the wafer bow. The subscripts Bi and Ai stand for before-implantation and after-implantation while FS and BS for front side and back side of the wafer.

The XRD spectra for the six implanted substrates are displayed in Fig. 1(a). The principal diffraction peak at $\mathrm{q}_{\mathrm{z}}$ represents the 220 reflection of the pristine Si substrate. For $\mathrm{q}<\mathrm{q}_{\mathrm{z}}$, we discern scattered intensities characterizing the presence of larger out-of-plane interplanar distances $d$. The observed fringe patterns are signatures of a variation of $d$ following a Gaussian-like distribution. ${ }^{26-30}$ The maximum out-of-plane strain $\varepsilon_{\perp}^{M A X}$ can be roughly estimated from the position of the fringe most distant from the Bragg's peak, indicating that strain increases with the implanted fluence. However, to extract precise values, and the complete depth-distribution profile of strain, a full simulation of the spectra is needed.

In Fig. 1(b) we display, for all the implanted fluences, the modeled depth-distribution profiles of $\varepsilon_{\perp}$ (full lines), and the depth-concentration profiles of $\mathrm{H}$ measured by SIMS (dashed lines). For low fluences, up to $\Phi=1 \times 10^{16} \mathrm{H} / \mathrm{cm}^{2}$, we observe a correlation between the evolution of strain and H-concentration (curves overlap). For fluences higher than $\Phi=2 \times 10^{16} \mathrm{H} / \mathrm{cm}^{2}$, the trend is not the same: strain increases faster than the $\mathrm{H}$ concentration. In the graph in Fig. 1(c), we plotted the integrated out-of-plane strain, which is also the vertical displacement of the surface, or swelling $u_{\perp}^{s}$, given as

$$
u_{\perp}^{s}=\int \varepsilon_{\perp} d z,
$$

with the direction $\mathrm{z}$ being normal to the substrate surface. The term $\int \varepsilon_{\perp} d z$ is obtained by integrating the area below the strain profiles in Fig. 1(b). Up to $\approx 1 \times 10^{16} \mathrm{H} / \mathrm{cm}^{2}$, we observe a linear relation of $u_{\perp}^{s}$ versus $\Phi$. For $\Phi>1 \times 10^{16}$ $\mathrm{H} / \mathrm{cm}^{2}, u_{\perp}^{s}$ grows faster, changing the slope of the quotient. For the highest fluence $\Phi=6 \times 10^{16} \mathrm{H} / \mathrm{cm}^{2}$ the displacement of the surface reaches $\approx 2.5 \mathrm{~nm}$.

In Fig. 1(d), we display the peak values of vertical strain $\varepsilon_{\perp}^{M A X}$ versus the local concentration of $\mathrm{H}$ for the different implanted samples. As for the displacements, strain increases linearly at low fluence regimes. From $\varepsilon_{\perp}^{M A X} \approx 0.055 \%$ at 0.36 at. \% of $\mathrm{H}\left(\Phi=0.25 \times 10^{16} \mathrm{H} / \mathrm{cm}^{2}\right)$ it rises up to $\varepsilon_{\perp}^{M A X}$ $\approx 0.21 \%$ for 1.42 at. $\%\left(\Phi=1 \times 10^{16} \mathrm{H} / \mathrm{cm}^{2}\right)$. For higher fluences, we observe a deviation, with strain developing faster and reaching up to $\varepsilon_{\perp}^{M A X} \approx 2.8 \%$ for a peak concentration of 11.2 at. $\%$ of $\mathrm{H}$. The slope of the deviation is higher for $\varepsilon_{\perp}^{M A X}$ than for $u_{\perp}^{s}$ (Fig. 1(c)). The latter includes the contribution of all strained regions, indicating that the effect is pronounced
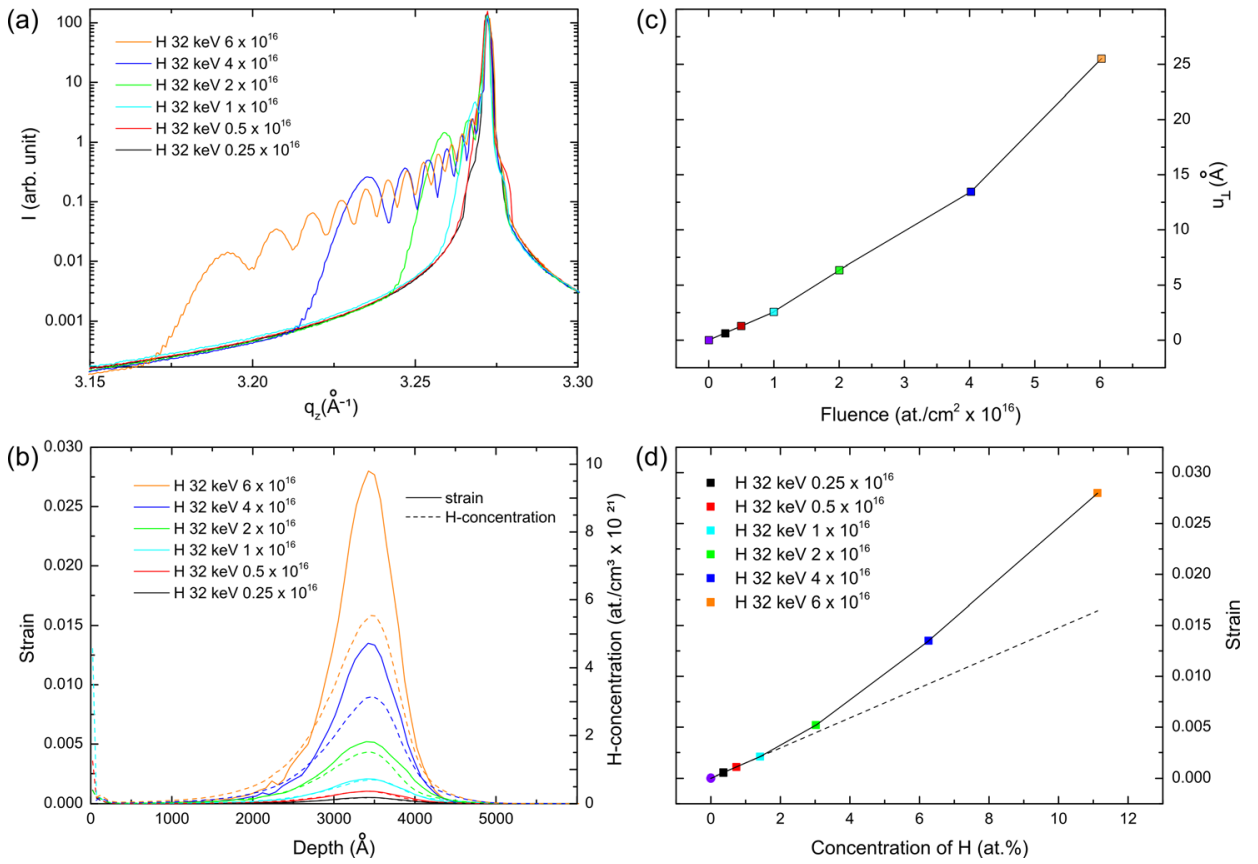

FIG. 1. (a) XRD spectra of H-implanted (110) Si around the 220 reflection of the of Si substrate. (b) Strain profiles in $\mathrm{H}$ implanted $\mathrm{Si}$ reconstructed from the XRD curves in Fig. 1(a) (solid lines) and the profiles of depth-concentration of $\mathrm{H}$ measured by SIMS (dashed lines). (c) Plot of the integrated strain $u_{\perp}$. (d) Maximum values of out-of-plane strain versus peak $\mathrm{H}$-concentrations, and linear extrapolation (dotted line) considering that $\nu_{\mathrm{i}}$ do not change and $\left(\frac{\Delta V}{V}\right)^{H}$ is constant and determined from the linear region of the experimental data; i.e., for a concentration of $\mathrm{H}<1.42$ at. \%. The different fluences are indicated by the color/symbol scheme of the legends. 
in the zones of higher H-concentration. From the linear part of the curve (i.e., $\leq 1.42$ at. \%), and taking $\nu_{\mathrm{i}}=0.21$ for (110) $\mathrm{Si}$, we can use Eq. (1) to estimate that the average dilatation induced by implanted $\mathrm{H}$ ions is $\left(\frac{\Delta V}{V}\right)^{H} \approx 0.03$. Then, in Fig. 1(d), we plotted the expected linear behavior of $\varepsilon_{\text {linear }}$ versus H-concentration assuming that $\left(\frac{\Delta V}{V}\right)^{H}$ is independent of the $\mathrm{H}$-concentration (dotted line).

In Fig. 2, we display the values of the biaxial in-plane stress in the film determined from the wafer bow measurements. The results are expressed in terms of ${ }^{32}$

$$
\int_{0}^{t_{l}} \sigma_{\|} d z=\frac{2 \mu_{s}\left(1+\nu_{s}\right) t_{s}^{2}}{\left(1-\nu_{s}\right) 6 R}
$$

where $t_{l}$ and $t_{s}$ are the thicknesses of the implanted layer and substrate, $\mu_{\text {sub }}$ is the shear modulus of the substrate (taken as $69 \mathrm{GPa}$ ) and $\nu_{\mathrm{s}}=0.21$ stands for the Poisson ratio of the substrate. The negative $\sigma_{\|}^{\text {mean }} t_{l}$ values show that the implanted region is under compressive stress. A linear increase of this stress is observed up to $\Phi=2 \times 10^{16} \mathrm{H}^{+} / \mathrm{cm}^{2}$. In contrast with the increasing out-of-plane strain, for high $\Phi$, the stress tends to saturate.

Analyzing the results obtained from XRD and SIMS, for high fluence regimes the difference between the experimentally measured out-of-plane strain and the expected values following a linear extrapolation from low fluences $\Delta \varepsilon_{\perp}$ $=\varepsilon_{\perp}-\varepsilon_{\perp}^{\text {linear }}$ (Fig. 1(d)) can in principle have two possible physical origins: (i) an evolution of the average Si lattice dilatation per implanted ion $\left(\frac{\Delta V}{V}\right)^{H}$ or (ii) a change in the Poisson ratio of the damaged material (see Eq. (1)).

For the case of $\mathrm{H}$ implantation in $\mathrm{Si}$, strain was shown to be intimately related to the depth concentration of $\mathrm{H}$ which is mainly found either in interstitial position or under H-vacancy complexes. From a thermodynamic perspective, an increasing density of such point defects created in the material tends to favor clustering, thus reducing the interfacial energy and eventually the occupied volume and elastic energy of the system. However, different complex type of defects formation and spatial distributions may generate an

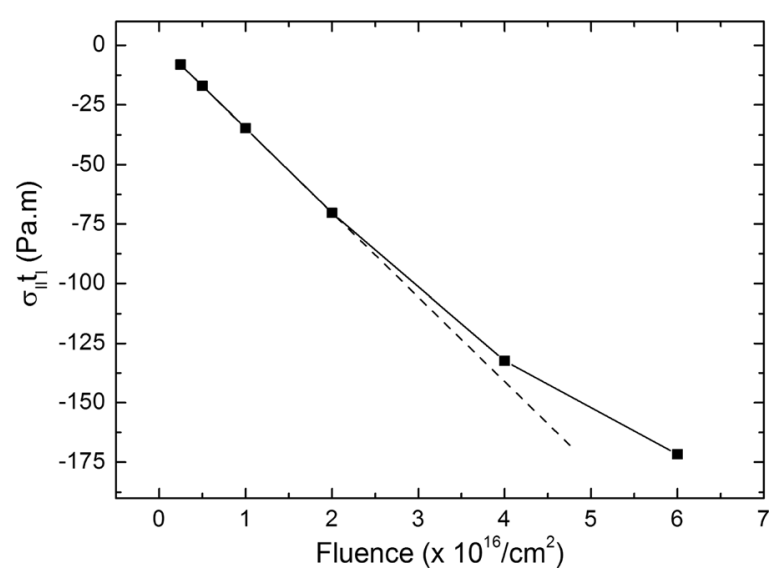

FIG. 2. Product stress-thickness $\sigma_{\|}^{\text {mean }} t_{l}$ determined from the measurements of wafer bow for the different implanted fluences. The dotted line represents a linear extrapolation from the points of low fluence. increase of $\left(\frac{\Delta V}{V}\right)^{H}$ for high fluence regimes. Considering that $\nu_{\mathrm{i}}$ is invariant with fluence/damage, $\left(\frac{\Delta V}{V}\right)^{H}$ must increase from approximately 0.03 for low fluences up to $\approx 0.055$ when the peak concentration of $\mathrm{H}$ reaches 11.2 at. \%.

Considering the second hypothesis, where $\left(\frac{\Delta V}{V}\right)^{H}$ remains linearly related to $\Phi$, we can calculate the change in $\nu_{i}^{M A X}$ which accounts for the change in the measured $\varepsilon_{\perp}^{M A X}$. When $\varepsilon_{\perp}$ first deviates from the linear relation found for low fluences, at the peak concentration of $\approx 3$ at. $\%$ of $\mathrm{H}$, we found that an increase of $\nu_{i}^{M A X}$ from 0.21 to 0.28 would compensate $\Delta \varepsilon$. For peak concentrations of $\approx 6.2$ at. $\%$ and 11.2 at. $\%, \nu_{i}^{M A X}$ rises to 0.38 and 0.44 , respectively. According to this hypothesis, the material eventually approaches the behavior of an incompressible solid $(\nu=0.5)$.

The variation of the Poisson coefficient is consistent with previous reports on elastic softening of materials under irradiation, reporting that the elastic constants can vary independently. ${ }^{22}$ Under elastic regime, the Poisson effect is essentially a macroscopic convolution of the interatomic distance modifications between orthogonal directions of a material under deformation. It contains therefore information on the correlation between neighboring atoms. As a consequence, perturbation of atomic bounds can impact the parameter. An increase in the Poisson ratio can be interpreted here in association with the disruption of atomic links, or crystal damage accumulation. In particular, the highest stressed/strained region of the implanted layer contains a significant density of lattice defects such as $\mathrm{Si}$ dangling bonds passivated by $\mathrm{H}$, hydrogenated vacancy complexes and nanoscopic cavities. This could reduce the correlation of $\mathrm{Si}$ atoms, and therefore the capacity to absorb elastic energy and a change volume under deformation. In the case of 11.2 at. $\%$ of $\mathrm{H}$ at the region of maximum $\mathrm{H}$ concentration, with an average of $0.8 \mathrm{H}$ atoms by Si lattice, a large density of uncorrelated Si atoms may be found. In the light of the present results, however, we are not able to definitively conclude whether the origin of $\Delta \varepsilon$ is from an increase in the lattice dilatation per implanted $\mathrm{H}$ ion, the increase of the Poisson ratio, or a combined effect.

The expression that relates both $\nu_{\mathrm{i}}$ and $\left(\frac{\Delta V}{V}\right)^{H}$ to the
tane stress $\sigma_{\|}$is given by in-plane stress $\sigma_{\|}$is given by

$$
\sigma_{\|}=-\frac{2}{3} \frac{\left(1+\nu_{i}\right) \mu_{i m p}}{\left(1-\nu_{i}\right)}\left(\frac{\Delta V}{V}\right)^{H},
$$

and denotes that if $\sigma_{\|}$tends to saturate with the implanted fluence (Fig. 3), and $\nu_{\mathrm{i}}$ and/or $\left(\frac{\Delta V}{V}\right)^{H}$ increases, the shear modulus $\mu_{i m p}$ of the implanted layer reduces.

We have therefore studied the evolution of $\mu_{\text {imp }}$ by associating the measurements of $\varepsilon_{\perp}$ from XRD with the stress determined from the wafer curvature. For this, the in-plane stress in the implanted layer can be calculated from the XRD as ${ }^{30,34}$

$$
\int_{0}^{t_{l}} \sigma_{\|} d z=-2 \mu_{i m p}^{e f f} \int_{0}^{t_{l}} \varepsilon_{z z} d z
$$

where the effective shear modulus $\mu_{i m p}^{e f f}$ is defined as a global value over the implanted layer. Combining Eqs. (3) and (5), 


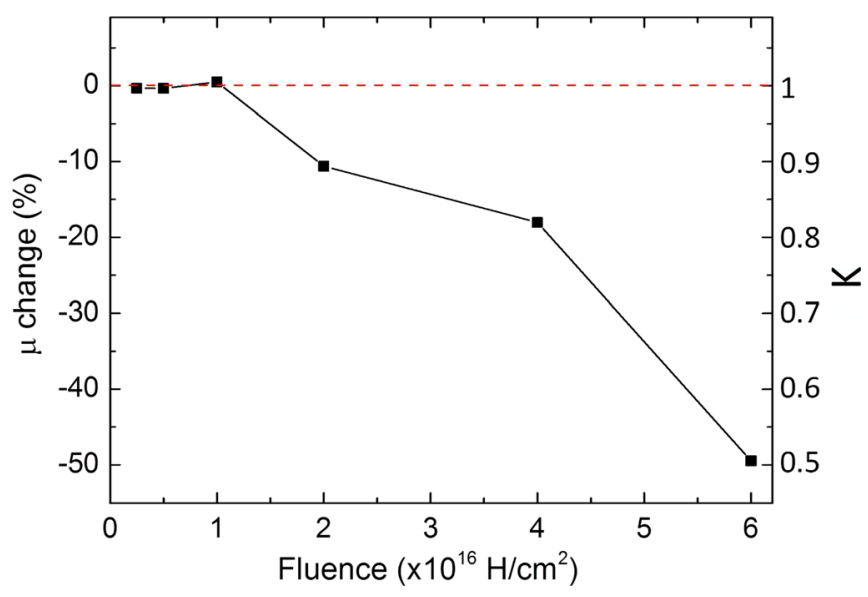

FIG. 3. Plot of the shear modulus $\mu$ change of the implanted layer with respect to the substrate versus the implanted fluence. The right axis informs on the value of the factor $\mathrm{K}$.

we define the coefficient $\mathrm{K}$ relating $\mu_{i m p}^{e f f}$ to the shear modulus of the bulk Si $\mu_{\text {sub }}$ as

$$
K=\frac{\mu_{i m p}^{e f f}}{\mu_{\text {sub }}}=-\frac{\left(1+\nu_{s}\right) t_{s}^{2}}{6\left(1-\nu_{s}\right) R u_{\perp}} .
$$

It follows from Eq. (6) that if $\mathrm{K}=1 \mu_{\text {imp }}^{\text {eff }}$ is unchanged with respect to $\mu_{\text {sub }}$, if $\mathrm{K}>1$ it increases, and if $\mathrm{K}<1$ it decreases. The graph in Fig. 3 displays, for different fluences, the percentage of deviation of $\mu_{i m p}^{\text {eff }}$ from $\mu_{\text {sub }}$. The right axis of the figure is the value of $\mathrm{K}$. This result shows that the shear modulus of the material is virtually unaffected by the implantations of $\mathrm{H}$ up to $\Phi=1 \times 10^{16} \mathrm{H}^{+} / \mathrm{cm}^{2}$. For $\Phi \geq 2 \times 10^{16}$ $\mathrm{H}^{+} / \mathrm{cm}^{2}$, we observe a reduction of $\mu_{i m p}^{\text {eff }}$. For instance, for $\Phi=6 \times 10^{16} \mathrm{H}^{+} / \mathrm{cm}^{2}$ the value of $\mu_{i m p}^{e f f}$ falls by a factor of two compared to the bulk Si. The local change in the highly damaged region of the layer would be indeed higher than the mean value. These experimental findings show that the ion implantation of $\mathrm{H}$ considerably modifies the mechanical properties of Si. This occurs at relatively low levels of crystalline damage compared to previous reports using heavy ion implantation in semiconductors. The mechanical properties of the material for a given fluence or H-concentration given here are valid for the as-implanted state, and certainly associated to the particular crystal damage produced by H-implantation.

The results presented here contribute to the understanding of the H-implantation fracture of $\mathrm{Si}$ from a micromechanics perspective providing important inputs in terms of the elastic properties of the material. The modification of local elastic parameters would, for example, affect the critical fracture toughness $K_{I C}$ of the material, and therefore the stress criterion for crack propagation for modeling the fracture processes. Such information becomes relevant because an increasing control of H-induced fracture of Si is necessary to produce SOI with ultrathin Si top layer for advanced device applications.

In conclusion, we have studied the effects of lattice damage introduced by $\mathrm{H}$-implantation in $\mathrm{Si}$ on the local mechanical properties of the material. For a series of implanted fluences, we measured the depth profile of $\mathrm{H}$ concentration, the corresponding biaxial stresses and out-ofplane strains in the implanted layer. We observed a supralinear behavior of strain for $\mathrm{H}$-concentrations $>1.4 \%$. This can be explained either by an evolution of the average dilatation introduced per implanted ion or by an evolution of the Poisson ratio of the material with increasing damage of the crystal. Using elasticity theory to combine independent stress and strain measurements, we show that $\mathrm{H}$-implantation causes a dramatic effect on the shear modulus of Si. The simple method developed here to study the modification of mechanical properties of $\mathrm{Si}$ under $\mathrm{H}$-implantation can be applied to other implanted systems/materials.

${ }^{1}$ N. Xu, B. Ho, F. Andrieu, L. Smith, B.-Y. Nguyen, O. Weber, T. Poiroux, O. Faynot, and T.-J. K. Liu, IEEE Electron Device Lett. 33(3), 318 (2012). ${ }^{2}$ S. Barraud, R. Coquand, M. Cassé, M. Koyama, J. M. Hartmann, V. Maffini-Alvaro, C. Comboroure, C. Vizioz, F. Aussenac, O. Faynot, and T. Poiroux, IEEE Electron Device Lett. 33(11), 1526 (2012).

${ }^{3}$ M. Schmidt, R. A. Minamisawa, S. Richter, A. Schëafer, D. Buca, J. M. Hartmann, Q.-T. Zhao, and S. Mantl, Appl. Phys. Lett. 101, 123501 (2012).

${ }^{4}$ M. Bruel, Electron. Lett. 31, 1201 (1995).

${ }^{5}$ B. Aspar, H. Moriceau, E. Jalaguier, C. Lagahe, A. Soubie, B. Biasse, A. M. Papon, A. Claverie, J. Grisolia, G. Benassayag, F. Letertre, O. Rayssac, T. Barge, C. Maleville, and B. Ghyselen, J. Electron. Mater. 30, 834 (2001).

${ }^{6}$ M. K. Weldon, V. E. Marsico, Y. J. Chabal, A. Agarwal, D. J. Eaglesham, J. Sapjeta, W. L. Brown, D. C. Jacobson, Y. Caudano, S. B. Christman, and E. E. Chaban, J. Vac. Sci. Technol. B 15, 1065 (1997).

${ }^{7}$ F. A. Reboredo, M. Ferconi, and S. T. Pantelides, Phys. Rev. Lett. 82(24), 4870-4873 (1999).

${ }^{8}$ J. Grisolia, G. Ben Assayag, A. Claverie, B. Aspar, C. Lagahe, and L. Laanab, Appl. Phys. Lett. 76, 852 (2000).

${ }^{9}$ L. Capello, F. Rieutord, A. Tauzin, and F. Mazen, J. Appl. Phys. 102, 026106 (2007).

${ }^{10}$ S. Reboh, A. A. de Mattos, J. F. Barbot, A. Declemy, M. F. Beaufort, R. M. Papaleo, C. P. Bergmann, and P. F. P. Fichtner, J. Appl. Phys. 105, 093528 (2009).

${ }^{11}$ G. Moras, L. C. Ciacchi, C. Elsässer, P. Gumbsch, and A. De Vita, Phys. Rev. Lett. 105, 075502 (2010).

${ }^{12}$ J.-D. Penot, D. Massy, F. Rieutord, F. Mazen, S. Reboh, F. Madeira, L. Capello, D. Landru, and O. Kononchuk, J. Appl. Phys. 114, 123513 (2013).

${ }^{13}$ S. Reboh, A. A. D. de Mattos, F. Schaurich, P. F. P. Fichtner, M. F. Beaufort, and J. F. Barbot, Scr. Mater. 65, 1045-1048 (2011).

${ }^{14}$ M. Nastasi, T. Höchbauer, J.-K. Lee, A. Misra, J. P. Hirth, M. Ridgway, and T. Lafford, Appl. Phys. Lett. 86, 154102 (2005).

${ }^{15}$ S. Reboh, J. F. Barbot, M. F. Beaufort, and P. F. P. Fichtner, Appl. Phys. Lett. 96, 031907 (2010).

${ }^{16}$ G. Parry, C. Coupeau, E. Dion, M.-L. David, J. Colin, and J. Grilhe, J. Appl. Phys. 110, 114903 (2011).

${ }^{17}$ H. Özkan, J. Appl. Phys. 47, 4772 (1976).

${ }^{18}$ M. Grimsditch, K. E. Gray, R. Bhadra, R. T. Kampwirth, and L. E. Rehn, Phys. Rev. B 35(2), 883 (1987).

${ }^{19}$ L. E. Rehn, P. R. Okamoto, J. Pearson, R. Bhadra, and M. Grimsditch, Phys. Rev. Lett. 59(26), 2987 (1987).

${ }^{20}$ E. K. Salje, Appl. Phys. Lett. 89, 131902 (2006).

${ }^{21}$ R. Bhadra, J. Pearson, P. Okamoto, L. Rehn, and M. Grimsditch, Phys. Rev. B 38(17), 12656 (1988).

${ }^{22}$ R. P. Sharma, R. Bhadra, L. E. Rehn, P. M. Baldo, and M. Grimsditch, J. Appl. Phys. 66, 152 (1989).

${ }^{23}$ P. Mutti, Z. Sklar, G. A. D. Briggs, and C. Jeynes, J. Appl. Phys. 77, 2388 (1995).

${ }^{24}$ R. C. Birtcher, M. H. Grimsditch, and L. E. McNeil, Phys. Rev. B 50(13), 8990 (1994).

${ }^{25}$ F. Gao and W. J. Weber, Phys. Rev. B 69, 224108 (2004).

${ }^{26}$ N. Cherkashin, S. Reboh, A. Lubk, M. J. Hÿtch, and A. Claverie, Appl. Phys. Express 6, 091301 (2013). 
${ }^{27}$ F. Rieutord, F. Mazen, S. Reboh, J. D. Penot, L. Bilteanu, J. P. Crocombette, V. Vales, V. Holy, and L. Capello, J. Appl. Phys. 113, 153511 (2013).

${ }^{28}$ N. Sousbie, L. Capello, J. Eymery, F. Rieutord, and C. Lagahe, J. Appl. Phys. 99, 103509 (2006).

${ }^{29}$ C. Miclaus and M. S. Goorsky, J. Phys. D 36, A177 (2003).

${ }^{30}$ S. Reboh, F. Schaurich, A. Declemy, J. F. Barbot, M. F. Beaufort, N. Cherkashin, and P. F. P. Fichtner, J. Appl. Phys. 108, 023502 (2010).
${ }^{31}$ M. Grundmann and A. Krost, Phys. Status Solidi B 218, 417-423 (2000).

${ }^{32}$ G. C. A. M. Janssen, M. M. Abdalla, F. van Keulen, B. R. Pujada, and B. van Venrooy, Thin Solid Films 517(6), 1858-1867 (2009).

${ }^{33}$ SEMI MF534, Test Method for Bow of Silicon Wafers (Semi International Standards, 2013).

${ }^{34}$ A. Debelle and A. Declémy, Nucl. Instrum. Methods Phys. Res. B 268, 1460-1465 (2010). 